\section{Lumbar vertebrae anomalies and their significance in a young gymnast}

\section{Heim and A. Blankstein}

Orthopaedic Consultants, Chaim Sheba Medical Centre, Tel-Hashomer Hospital, Israel 52621

The Orthopaedic Department is affiliated to the Sackler School of Medicine, University of Tel Aviv

\section{Sir}

We recently examined an 11-year-old girl at the request of her parents and their general practitioner. The child is a tall thin girl who excelled in school during physical education classes. Her teacher, recognizing the child's potential, encouraged her to join a sports establishment and for the last 5 years the child has been involved not only in gymnastics but also, of her own volition, in modern dancing. The child had no complaints whatsoever until a few months ago when she landed 'badly' on her heels after a somersault. On examination, no heel or back pathology could be found and the patient underwent a bone scan and $\mathrm{X}$-ray. The bone scan was normal and the X-ray plates are shown in Figure 1. It would appear that incomplete segmentation has occurred ${ }^{1}$ between L2-3, L3-4 and L4-5, with obvious narrowing of the disc spaces and developmental damage to part of the disc and epiphyseal plate. The disc space L5-S1 is markedly enlarged. It has been suggested that 'this anomaly may predispose to disc derangement proximal to the fusion mass and possibly to premature degenerative changes in the distal posterior intervertebral joints ${ }^{2}$. In view of the $X$-ray anomalies, the child, now asymptomatic, was re-examined. This young girl was able, while standing with extended knees, to place her palms flat on the ground in front of her. There were no signs of any lumbar spinal restriction of movements. One individual in 20 has an abnormality of segmentation in the lumbosacral area ${ }^{2}$ and hence the relevance of this problem in the sporting community is significant.

The parents, noting our concern, enquired whether in our opinion their daughter, a talented child, should continue with gymnastics? We faced a moral dilemma and hence perhaps ask whether the Journal would consider publishing this letter and a relevant reply.

1 Davies D, Davies F. Grays Anatomy, 33 ed. London: Longman, 1969: 120 .

2 Murray R, Jacobson H. The Radiology of Skeletal Disorders, 2nd ed. Edinburgh, London, New York: Churchill Livingstone, 1977: 6-17.

\section{Reply}

\section{J. F. Dooley BSc, MB, FRCS, FRCS(C)}

Consultant Orthopaedic Surgeon, Hillingdon Hospital, Uxbridge, Middlesex UB8 3NN, UK

\section{Sir}

The Editor has kindly asked me to comment on your letter 'Lumbar vertebrae anomalies and their significance in a young gymnast'. From the $X$-rays supplied it would appear that this patient has apophysitis of the anterior aspect of the ring apophysis at L2-3 and L3-4. At L4-5 there appears to be some anterior discitis and discogenic sclerosis. The shape of this vertebra makes me wonder about this young

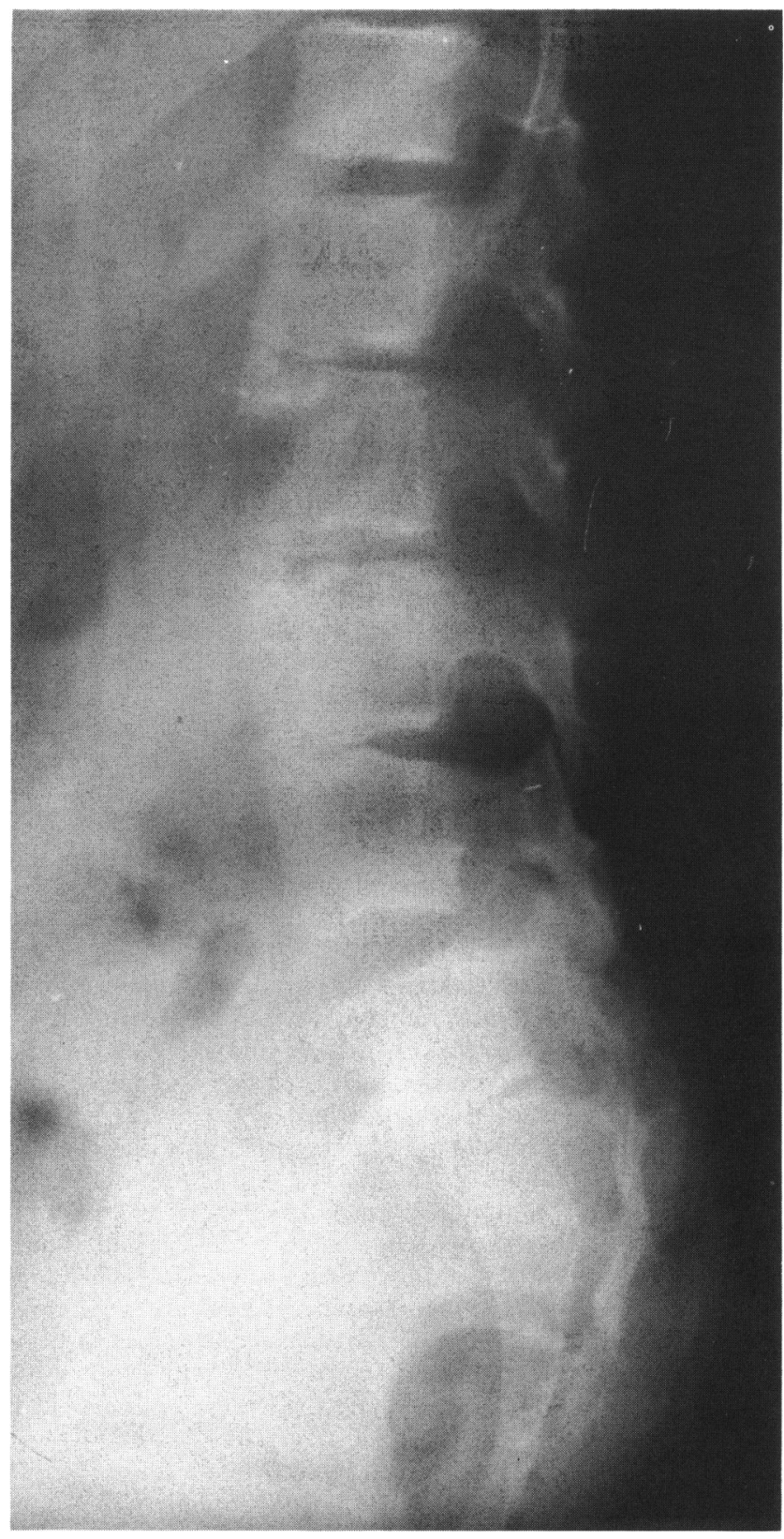

Figure 1. X-ray plates of patient

lady having ankylosing spondylitis or DISH. I agree that the disc at L5-S1 appears enlarged due to the disc height at the other levels. This may also be due to the decrease in her lumbosacral angle.

It would be interesting to see follow-up radiographs to monitor the progression of her disorder. Your letter does not state whether this child did experience any symptoms so it is difficult to decide whether she should modify her activity. Patients with this form of discitis are usually capable of performing many sporting activities without aggravating the condition.

It has been my experience to allow these children to continue playing those sports which do not aggravate back symptoms. In this case, if the patient has been performing gymnastics, I would certainly allow her to continue. Further follow-up radiographs would be most interesting. 